\title{
Interval exercise training improves tissue oxygenation in patients with chronic heart failure
}

\author{
Ioannis Vasileiadis ${ }^{1}$, Maria Kravari ${ }^{1}$, John Terrovitis ${ }^{2}$, Vasiliki Gerovasili ${ }^{1}$, Stavros Drakos ${ }^{2}$, \\ Argyrios Ntaliannis ${ }^{2}$, Stavros Dimopoulos ${ }^{1}$, Maria Anastasiou-Nana ${ }^{2}$, Serafim Nanas ${ }^{{ }^{*}}$ \\ ${ }^{1}$ Pulmonary \& Critical Care Medicine Department, Cardiopulmonary Exercise Testing and Rehabilitation Laboratory, "Evgenidio" \\ Hospital, National and Kapodistrian University of Athens, Athens, Greece \\ ${ }^{2}$ Third Cardiology Department, National and Kapodistrian University of Athens, Athens, Greece \\ Email: ${ }^{*}$ a.icusn@gmail.com
}

Received 5 January 2013; revised 6 February 2013; accepted 20 February 2013

\begin{abstract}
Aim: Aim of our study was to evaluate the effects of interval exercise training (IT) programs, regarding whole body oxygen uptake and peripheral tissue oxygenation, in Chronic Heart Failure (CHF) patients during recovery. Methods: Twenty-six CHF patients (21 males/5 females), mean age of $49 \pm 12$ years, participated in the study. Fifteen patients were assigned to IT and 11 patients were assigned to IT followed by strength training. All patients were trained for $\mathbf{4 0}$ minutes per session, 3 times per week, for 12 weeks. They performed a symptom-limited cardiopulmonary exercise testing (CPET), before and after the completion of the program. Muscle tissue oxygen saturation $\left(\mathrm{StO}_{2}\right)$ of quadriceps femoris was continuously measured by Near Infrared Spectroscopy (NIRS) during CPET and during the recovery period after the end of exercise. Results: No differences were noted between the two patient groups regarding whole body and peripheral tissue oxygenation indices and, therefore, data from all patients were pooled. After training, an increase in peak oxygen uptake $(17 \pm 4.5$ to $19 \pm 5.5$ $\mathrm{ml} / \mathrm{kg} / \mathrm{min}, \mathrm{p}<0.05)$, gas exchange threshold (11 \pm 3.5 to $12.5 \pm 3.5 \mathrm{ml} / \mathrm{kg} / \mathrm{min}, \mathrm{p}<0.05)$, peak work rate achieved (105 \pm 29 to $124 \pm 37$ Watt, $p<0.05)$ and the first degree slope of $\mathrm{VO}_{2}$ at the first minute of recovery $\left(0.45 \pm 0.2\right.$ to $\left.0.61 \pm 0.3 \mathrm{~L} / \mathrm{min}^{2}, \mathrm{p}<0.05\right)$, was noted. In addition, tissue re-oxygenation time constant was decreased ( $65 \pm 25$ to $52 \pm 28 \mathrm{sec}, \mathrm{p}<0.001)$. Conclusion: In conclusion, interval exercise training accelerates oxygen uptake and peripheral tissue oxygenation during recovery from exercise in CHF patients.
\end{abstract}

Keywords: Heart Failure; NIRS; Tissue Oxygenation; Exercise Training

"Corresponding author.

\section{INTRODUCTION}

Patients with congestive heart failure (CHF) experience dyspnea and early fatigue during their daily activities and especially during exercise. Potentially responsible factors for this exercise intolerance are the reduced cardiac output and peripheral blood flow as well as peripheral muscle abnormalities including reduction of slow-twitch, type-I fibres, decreased activity of aerobic enzymes and contractile protein changes, decreased capillary density with peripheral muscle underperfusion, and peripheral vascular dysfunction that stems from the heightened sympathetic output in CHF, impaired release of vasoactive substances, decreased microvascular reactive recruitment and endothelial dysfunction [1-3].

Physical training of patients with heart failure has a beneficial effect on clinical symptoms, exercise tolerance, central and peripheral hemodynamics, ventilation, autonomic function, peripheral muscle histology and metabolic responses $[1,4]$. Also, it reduces inflammatory markers in plasma and peripheral muscles [5] and improves the kinetics of oxygen uptake [6]. Exercise training has been used in CHF patients with favorable outcome. Although continuous aerobic exercise training is usually applied, the interval method causes greater exercise stimulation to peripheral muscle without inducing greater cardiovascular stress [7]. Resistance training has been recommended when small muscle groups are involved using short bouts of work phases and small numbers of repetitions [8]. In a recent study we showed that combined aerobic interval and strength training induces a greater benefit than interval training alone on muscle strength in CHF patients [9].

Our hypothesis was that exercise training would improve whole body oxygen uptake in CHF patients. In addition, since the improved muscle oxygen delivery and utilization may be reflected upon the microcirculation functional indices of the tissue under consideration, exercise training would also improve microcirculation 
parameters in contracting muscles. Near Infrared Spectroscopy (NIRS) is used to evaluate the peripheral muscle microcirculation at rest and during exercise [10,11]. Aim of the study was to assess the effect of IT with and without strength training on whole body oxygen uptake and peripheral tissue oxygenation during recovery after a symptom-limited cardiopulmonary exercise testing (CPET).

\section{METHODS}

\subsection{Experimental Approach to the Problem}

The study was designed as a randomized controlled parallel two group study. The patients enrolled in the study were randomly assigned, according to oxygen uptake at peak exercise $\left(\mathrm{VO}_{2}\right.$ peak, cut-off $\left.16 \mathrm{ml} / \mathrm{kg} / \mathrm{min}\right)$ and age (cut-off 50 years), to interval aerobic or combined interval aerobic plus strength exercise training program, so that the two groups were stratified, and attended a three month rehabilitation program. Patients were excluded from the study if there was any contraindication for a cardiopulmonary exercise testing (CPET) according to the American Thoracic Society/American College of Chest Physicians guidelines.

All patients included in the study performed a symptom-limited, ramp-incremental CPET before and after the training program.

Gas exchange measurements during CPET served to calculate $\mathrm{VO}_{2}$ peak, anaerobic threshold (AT), peak work rate (WRpeak) and oxygen uptake during the first minute of recovery period $\left(\mathrm{VO}_{2} / \mathrm{t}\right.$-slope $)$. All these measurements provide quantitative indices of patients' functional status before and after the implementation of the rehabilitation program, especially $\mathrm{VO}_{2}$ /t-slope during early recovery which has been related with the restoration rate of energy stores in contracting muscles [12].

In order to non-invasively assess microcirculatory alterations we used the NIRS method. With a sensor placed on the surface of the skin, NIRS uses the principles of light spectroscopy to measure tissue oxygen saturation $\left(\mathrm{StO}_{2}\right)$, assessed by the percentage of oxygenated haemoglobin in all tissue vascular compartments (arterial, capillary, venous). Certain light-absorbing molecules (chromophores), such as haemoglobin, myoglobin and cytochrome oxidase, absorb light differently according to their oxygenation status, producing characteristic absorption spectra. However, NIRS signal is considered to derive mainly from hemoglobin. Differences in the oxygendependent absorption spectra thus reflect changes in oxygenation at the level of small blood vessels and provide in vivo estimates of the balance between oxygen supply and oxygen consumption. NIRS technique operates in real time and monitors continuously changes in the status of tissue oxygenation [10,13]. A common measurement made with NIRS is muscle oxygenation during exercise. A variety of muscles have been evaluated [14,15]. Oxygenation indices provided by NIRS, especially under the stress of exercise, can be used to estimate functional status of healthy people; also, to recognize and track microcirculatory and metabolic derangements in disease [16].

\subsection{Subjects}

The study population consisted of 26 patients ( 21 males, 5 females) with stable CHF referred to our laboratory by their treating physicians, in order to participate in the rehabilitation program. The diagnosis of CHF was based on clinical evaluation and laboratory testing utilizing non-invasive and invasive tests, including electrocardiogram (ECG), chest roentgenogram, echocardiogram, right heart catheterization, radionuclide ventriculography, coronary angiography and myocardial biopsy, as clinically indicated. Patient's mean age was $49 \pm 12$ years. Body Mass Index (BMI) of patients was the same before and after the training program $\left(26 \pm 4.8\right.$ vs $26 \pm 4.5 \mathrm{~kg} / \mathrm{m}^{2}$ respectively). The New York Heart Association functional classification of patients was: NYHA I: 3 patients, NYHA II: 15 patients, NYHA III: 8 patients. They were under treatment with angiotensin-converting enzyme (ACE) inhibitors $(n=23), \beta$-adrenergic blockers $(n=22)$, diuretics $(n=24)$, digoxin $(n=6)$, amiodarone $(n=9)$. One of the patients with a history of type II diabetes mellitus was receiving oral anti-diabetic treatment. All patients gave informed consent and the protocol was approved by the Institutional Research Review Panel of "Evgenidion" Hospital on issues of ethics, health and safety.

\subsection{Procedures}

\subsubsection{Exercise Prescription}

All participants underwent aerobic training on electromagnetically braked cycle ergometer (Cateye Ergociser, EC1600; Tokyo, Japan), with or without strength training, three times per week, for 12 weeks and a total of 36 sessions. Any missed sessions were added at the end of the rehabilitation program, so that all 36 sessions were completed. Fifteen patients were assigned to interval training (IT) that included alternations of $30 \mathrm{sec}$ of exercise with $60 \mathrm{sec}$ of rest, for a $40 \mathrm{~min}$ period and 11 patients were assigned to IT for $20 \mathrm{~min}$ followed by strength training for $20 \mathrm{~min}$. Thus, both groups were trained for $40 \mathrm{~min}$ per session. Interval exercise involves short periods with high work rates. A special test, the steep ramp test, was utilized to define the patients' maximum exercise capacity over this short time period and to derive intensity levels for interval exercise. Steep ramp test was performed at the start of the study to determine the initial 
training work rate, then weekly to readjust it. The maximum work rate achieved from this test increased weekly and thus the training work rate increased accordingly $[7,8]$. The exercise intensity was set at $50 \%$ of work load achieved at the steep ramp test. Strength training included exercises for the quadriceps [1 - 3 sets, 10 - 12 repetitions, 55\% - 65\% 2-Resistance-Maximum (2-RM)], the hamstrings ( 1 - 3 sets, 10 - 12 repetitions, 55\% - 65\% 2-RM of quadriceps minus $0.5-1 \mathrm{~kg}$ ), the deltoid and muscles of the shoulder zone ( 1 - 3 sets, 10 - 12 repetitions, $100 \% 10-\mathrm{RM}$ ) and the biceps brachialis (1 - 3 sets, 10 - 12 repetitions, 100\% 10-RM). Supervision during exercise sessions was conducted by physical therapists, exercise physiologists and physicians and included continuous recording of ECG, periodical blood pressure measurements (at the $6^{\text {th }}, 20^{\text {th }}$ and $38^{\text {th }} \mathrm{min}$ ) and peripheral oxygen saturation monitoring.

\subsubsection{Cardiopulmonary Exercise Testing}

All patients, before and after the completion of the training program performed a symptom-limited, ramp-incremental CPET on an electro-magnetically braked cycle ergometer (Ergoline 800; Sensor Medics, Anaheim, California, USA).

In order to attain test duration of 8 - $12 \mathrm{~min}$, the work rate increment was estimated by using Hansen et al.'s equation [17]. Gas exchange was assessed while the patient was breathing through a low resistance valve with the nose clamped, using a model $\mathrm{V}_{\max }-229$ instrument (Sensormedics, Yorba Linda, California, USA) calibrated with a known gas mixture before each test. Oxygen uptake $\left(\mathrm{VO}_{2}\right)$, carbon dioxide output $\left(\mathrm{VCO}_{2}\right)$ and ventilation (VE) were measured breath-by-breath with the online system.

All measurements were recorded for $2 \mathrm{~min}$ at rest and for 2 min of unloaded pedalling before exercise, throughout exercise, and for the first 5 min of recovery. Baseline $\mathrm{VO}_{2}$ was the average of measurements for $2 \mathrm{~min}$ before exercise with the patient standing. Ventilation frequency was recorded throughout the exercise test and during recovery. Peripheral $\mathrm{O}_{2}$ saturation was monitored continuously by pulse oxymetry. Heart rate (HR) and rhythm were monitored by a MAX1, 12-lead ECG system (model 2000, Marquette Electronics, Milwaukee, USA) and blood pressure was measured every 2 min with a mercury sphygmomanometer. All patients were verbally encouraged to exercise to exhaustion, as defined by intolerable leg fatigue or dyspnoea.

\subsubsection{Cardiopulmonary Measurements}

The peak value for $\mathrm{VO}_{2}$ was calculated as the average of measurements made during the $20 \mathrm{sec}$ period before exercise was terminated. The AT was determined using the V-slope technique [18] and the result was confirmed gra- phically from a plot of ventilatory equivalents for oxygen $\left(\mathrm{VE} / \mathrm{VO}_{2}\right)$ and carbon dioxide $\left(\mathrm{VE} / \mathrm{VCO}_{2}\right)$ against time. Peak work rate was defined as the highest work level achieved and maintained at a pedalling frequency of no less than $50 \mathrm{rpm}$ for $30 \mathrm{sec}$. In order to examine $\mathrm{VO}_{2}$ kinetics during the early recovery phase, the first-degree slope of $\mathrm{VO}_{2}$ for the first minute of recovery $\left(\mathrm{VO}_{2} /\right.$ t-slope) was calculated as described in previous studies [19] by a linear regression model, using an appropriate computerized statistical program.

\subsubsection{NIRS Measurements}

The light transmitted from the NIRS probe used in this study has a penetration depth of approximately $2.5 \mathrm{~cm}$, thus enabling the measurement of $\mathrm{StO}_{2}$ in the respective muscle [11]. To record NIRS signal, the NIRS sensor (Inspectra 325, Hutchinson Tech, USA) was placed over the right vastus medialis (of the quadriceps femoris) muscle, approximately $15 \mathrm{~cm}$ from the patella, along the vertical axis of the thigh. Probe positioning over the quadriceps femoris muscle (vastus lateralis and vastus medialis) has been used by many investigators providing reliable results [10].

The $\mathrm{StO}_{2}$ was continuously monitored at rest, during the maximal cardiopulmonary exercise testing and during the recovery period after the end of exercise. The values from the quadriceps muscle were continuously monitored and stored into computer using the "In Spectra" software. $\mathrm{StO}_{2}$ curves were analyzed by "In Spectra Analysis Program version 2.0 (Hutchinson Technology, USA.) running in Mat Lab 7.0 (Math Works, USA)" (Figure 1). Linear regression was used to extrapolate the oxygen desaturation rate $(\% / \mathrm{min})$ of the quadriceps muscle during exercise and the oxygen resaturation rate $(\% / \mathrm{min})$ during the early recovery period after the end of exercise. Also, the $\mathrm{StO}_{2}$ data during recovery were analyzed using a mono-exponential plus delay mathematical model: $\mathrm{StO}_{2}(\mathrm{t})=\mathrm{StO}_{2}(\mathrm{~b})+\mathrm{A}\left(1-\mathrm{e}^{-(\mathrm{t}-\mathrm{TD}) / \tau)}\right)$ and an appropriate computerized program, as in previous studies [10] where $\mathrm{StO}_{2}(\mathrm{~b})$ is the muscle oxygenation when recovery starts, A is the muscle oxygenation at the end of recovery, $\tau$ is the time constant and TD is the time delay.

All NIRS measurements were performed before and after the completion of the 36 session rehabilitation program.

\section{STATISTICAL ANALYSIS}

All continuous variables are presented by mean \pm SD. The within patient changes were evaluated by the Student's paired t-test or Wilcoxon test. Differences between patients were compared using Student's paired t-test for independent variables. Correlations between variables were tested by Pearson's correlation coefficient. The statistical significance of $\mathrm{p}$ value was set at $\mathrm{p}<0.05$. 


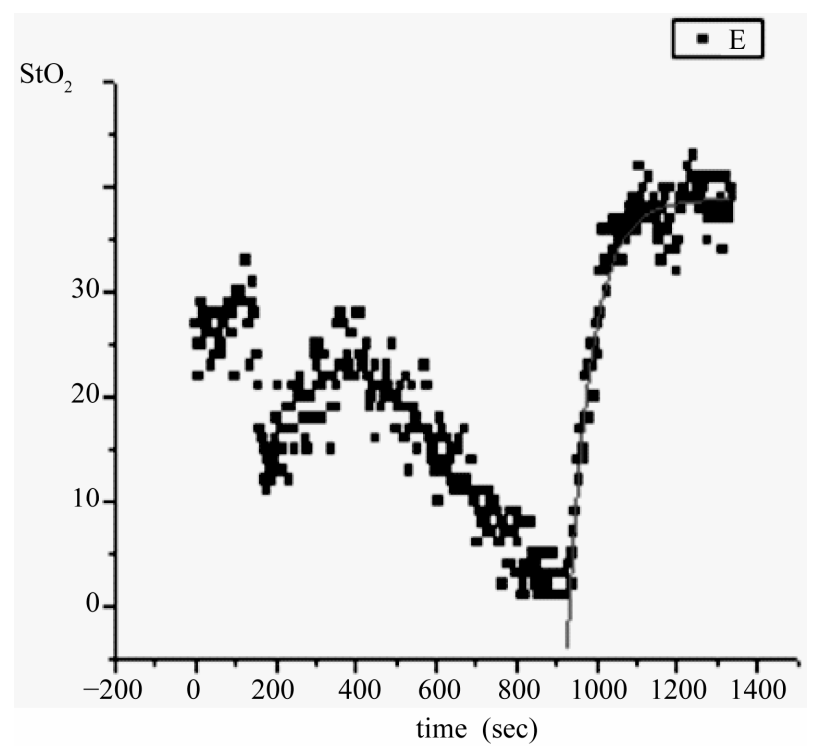

Figure 1. NIRS $\mathrm{StO}_{2}$ measurements during maximal exercise testing. Dots represent tissue oxygenation measurements during the exercise and recovery periods, elaborated by the computerized statistical program and graphically depicted. Continuous line represents the exponential curve of best fit.

\section{RESULTS}

There was no difference between the two patient training groups after the completion of the rehabilitation program (data not shown) and therefore data from all patients were pooled.

Although the present study did not specifically investigate gender differences, there was no significant difference between males and females concerning the training effect in whole body and tissue oxygen kinetics.

After training the parameters of cardiopulmonary exercise testing were improved. Specifically, peak oxygen uptake, oxygen uptake at the AT and peak work-rate were all significantly increased (Table 1). The $\mathrm{VO}_{2} /$ WR slope did not change significantly after training. Moreover, the oxygen cost of work at peak exercise was the same for the patients before and after training. Most importantly, early recovery oxygen uptake kinetics were accelerated (increased $\mathrm{VO}_{2}$ /t-slope, Table 1).

Goodness of fit $\left(\mathrm{R}^{2}\right)$ for the tissue re-oxygenation kinetics was $0.91 \pm 0.03$ for the patients before the training program, $0.90 \pm 0.04$ for the patients after the training program. $\mathrm{StO}_{2}$ at rest was the same before and after the training program $(47 \% \pm 18 \%$ vs $47 \% \pm 15 \%, p=0.9)$. $\mathrm{StO}_{2}$ of the quadriceps muscle measured at the end of the warm up period did not significantly change after completion of the rehabilitation program $(42 \% \pm 10 \%$ to $45 \%$ $\pm 17 \%, \mathrm{p}=0.4)$, as well as the $\mathrm{StO}_{2}$ at peak exercise $(22 \% \pm 17 \%$ to $18.6 \% \pm 15 \%, \mathrm{p}=0.37)$ and the $\mathrm{StO}_{2}$ decrease rate during exercise $(2.5 \pm 1.8$ to $3.6 \pm 3.4$ $\% / \min , \mathrm{p}=0.4$ ).
The time constant $(\tau)$ of the exponential curve describing tissue re-oxygenation during recovery was lower $(65 \pm 25$ to $52 \pm 28 \mathrm{sec}, \mathrm{p}<0.001)$ after exercise training. There was no correlation between parameters of cardiopulmonary exercise testing and $\tau$.

\section{DISCUSSION}

The main novel finding of our study was that, in CHF patients, tissue oxygen kinetics estimated by NIRS improved after exercise training. In particular, the time constant of the exponential curve that describes the restoration of tissue oxygenation during recovery decreased after the completion of the rehabilitation program. In addition, a substantial improvement of total body oxygen uptake kinetics, as assessed by the $\mathrm{VO}_{2} / \mathrm{t}$-slope during early recovery, was observed.

Prolonged oxygen kinetics (both, in muscle and total body oxygenation) have been demonstrated by other studies in CHF patients [20,21]. Also, in a previous study in CHF patients, we demonstrated a similar training effect on peripheral muscle re-oxygenation after a constant load, submaximal CPET [22].

Oxygen recovery kinetics are more reproducible than oxygen onset kinetics and may, more reliably, assess the functional impairment in CHF [23]. Acceleration, by training, of oxygen uptake kinetics during early recovery has been shown to strongly correlate with improvement of established indices of exercise capacity [24].

In our study we utilized an interval training program which enables patients with heart failure to train for shorter periods at higher intensity compared with a continuous exercise program. Interval exercise training produces superior effects than moderate continuous training in CHF patients, regarding the peak oxygen uptake, left ventricular reverse remodeling, flow-mediated arterial dilatation (endothelial function) and mitochondrial function [25].

Just recently, we have shown that the addition of strength training to the interval training regimen in CHF patients confers more beneficial effects in terms of muscle strength [9] and endothelial function [26], than interval training alone. However, in the present study, there was no significant difference in tissue oxygenation indices between the two training groups. The small number of participants might have influenced the results.

Acceleration, by training, of $\mathrm{Hb}$ resaturation in recovery could be attributed to an increase of oxygen delivery and/or to a faster decrease of the metabolic rate in myocytes. An expedited rate of adjustment of oxidative metabolism to a lower level, regarding the metabolic demands, results in a faster decrease of oxygen consumption and, accordingly, of oxygen extraction from tissue capillaries. This leads finally to a faster restoration of the 
Table 1. Cardiopulmonary exercise testing parameters in CHF patients before and after a 3-month rehabilitation program.

\begin{tabular}{|c|c|c|c|}
\hline \multirow[b]{2}{*}{ CPET parameters } & \multicolumn{2}{|c|}{ CHF patients $(n=26)$} & \multirow[b]{2}{*}{$\mathbf{p}$} \\
\hline & Before rehabilitation & After rehabilitation & \\
\hline $\mathrm{VO}_{2}$ peak, $(\mathrm{ml} / \mathrm{kg} / \mathrm{min})$ & $17 \pm 4.5$ & $19 \pm 5.5$ & $\mathrm{p}<0.05$ \\
\hline $\mathrm{VO}_{2}$ peak, $(\mathrm{ml} / \mathrm{kg} / \mathrm{min})$ pred $(\%)$ & $54 \pm 15$ & $62 \pm 17$ & $\mathrm{p}<0.05$ \\
\hline $\mathrm{VO}_{2} \mathrm{AT},(\mathrm{ml} / \mathrm{kg} / \mathrm{min})$ & $11 \pm 3.5$ & $12.5 \pm 3.5$ & $\mathrm{p}<0.05$ \\
\hline VEpeak, (L/min) & $63 \pm 14$ & $75 \pm 22$ & $\mathrm{p}<0.05$ \\
\hline $\mathrm{VE} / \mathrm{VCO}_{2}$ slope & $31 \pm 5$ & $30 \pm 9$ & $\mathrm{~ns}$ \\
\hline $\mathrm{VE} / \mathrm{VO}_{2}$ slope & $26 \pm 7$ & $23 \pm 7$ & ns \\
\hline WRpeak, (watt) & $105 \pm 29$ & $124 \pm 37$ & $\mathrm{p}<0.05$ \\
\hline Oxygen pulse, (ml/b) & $10.4 \pm 2.8$ & $11.1 \pm 3.4$ & ns \\
\hline $\mathrm{VO}_{2} / \mathrm{WR}$ at peak exercise, $(\mathrm{ml} / \mathrm{Kg} \cdot \mathrm{min} \cdot \mathrm{watt})$ & $0.167 \pm 0.042$ & $0.163 \pm 0.039$ & ns \\
\hline $\mathrm{VO}_{2} / \mathrm{WR},(\mathrm{ml} / \mathrm{min} \cdot \mathrm{watt})$ & $10.6 \pm 2.5$ & $9.4 \pm 2.6$ & ns \\
\hline $\mathrm{VO}_{2} / \mathrm{t}$-slope, $\left(\mathrm{L} / \mathrm{min}^{2}\right)$ & $0.45 \pm 0.2$ & $0.61 \pm 0.3$ & $\mathrm{p}<0.05$ \\
\hline
\end{tabular}

Values are presented as mean $\pm \mathrm{SD}$. $\mathrm{VO}_{2}$ peak: peak oxygen uptake; $\mathrm{AT}$ : anaerobic threshold; VEpeak: ventilation at peak of exercise; $\mathrm{VE} / \mathrm{VCO} 2$ : slope of ventilatory equivalent for carbon dioxide output; $\mathrm{VE} / \mathrm{VO}_{2}$ : slope of ventilatory equivalent for oxygen uptake; WRpeak: peak work rate; $\mathrm{VO}_{2} / \mathrm{WR}$ : the slope of the linear part of the curve describing absolute oxygen uptake $\left(\mathrm{ml} / \mathrm{min}\right.$ ) per unit of work-rate (watt); $\mathrm{VO}_{2} / \mathrm{t}$-slope: the first degree slope of $\mathrm{VO}_{2}$ for the first minute of recovery; The level of significance was set at $\mathrm{p}<0.05$. $\mathrm{p}$ value, comparing CHF patients before and after rehabilitation.

tissue oxygen saturation.

The debate on whether oxygen kinetics during transition to a new metabolic level is determined by intrinsic properties of oxidative metabolism or by oxygen delivery is long lasting. A usual approach to the problem has been to define whether the adjustment of oxygen delivery is faster than the adjustment of oxygen utilization. This approach, related to the so called "dissociation" of oxygen supply and utilization kinetics, has resulted in several contradictory views [27,28].

Investigations have established beneficial effects of exercise training on both, oxygen delivery in tissues and oxidative capacity of peripheral muscles.

In particular, training improves central haemodynamics [4], as well as blood flow in peripheral muscles, either by affecting neurohormonal mechanisms (such as renin activity, circulating cateholamines, natriuretic peptides and arginine-vasopressin) or by correcting endothelial dysfunction $[1,29,30]$. These changes reduce peripheral vascular resistance and increase blood flow to various organs, including skeletal muscles, especially during exercise.

Additionally, physical training increases the total volume density of cytochrome c oxidase-positive mitochondria and aerobic capacity in CHF patients [31]. Also, Adamopoulos et al. [32] demonstrated that training significantly increased exercise tolerance with less perturbation of adenylates and phosphocreatine concentration at all matched submaximal workloads and at peak exercise. Both effects could possibly account for an expe- dited rate of adjustment of intracellular metabolism (oxygen consumption and high energy phosphate kinetics) during work transitions.

This accelerated adjustment is also indirectly implied by the faster $\mathrm{VO}_{2}$ reduction during early recovery in our patients after training. In $\mathrm{CHF}$ patients, the recovery of energy stores is delayed in parallel with $\mathrm{VO}_{2}$ recovery [12]. As it has been shown that kinetics for both oxygen uptake and high energy phosphates cohere significantly, oxygen uptake kinetics can track changes of oxidative metabolism [33].

\section{CONCLUSION}

This study demonstrates that the whole body oxygen uptake and peripheral muscle tissue re-oxygenation, during recovery from maximal CPET, improved after a 3month rehabilitation program in $\mathrm{CHF}$ patients.

\section{LIMITATIONS-PERSPECTIVES}

The limitations of this study are the small number of CHF patients that may not allowed an existing difference between the two training groups to emerge, although it did not prevent the establishment of the beneficial effect of training on the whole, and the inherent limitations of the method to provide absolute measurements of tissue oxygenation.

A larger study is necessary in order to address the possible differential exercise training effects of the two training groups concerning tissue oxygenation in $\mathrm{CHF}$. 


\section{ACKNOWLEDGEMENTS}

This study was funded partly by a grant from the special account for research grants of the National and Kapodistrian University of Athens, Athens, Greece.

\section{REFERENCES}

[1] Duscha, B.D., Schulze, P.C., Robbins, J.L. and Forman, D.E. (2008) Implications of chronic heart failure on peripheral vasculature and skeletal muscle before and after exercise training. Heart Failure Reviews, 13, 21-37. doi:10.1007/s10741-007-9056-8

[2] Chong, A.Y., Blann, A.D., Patel, J., Freestone, B., Hughes, E. and Lip, G.Y. (2004) Endothelial dysfunction and damage in congestive heart failure. Relation of flow-mediated dilation to circulating endothelial cells, plasma indexes of endothelial damage, and brain natriuretic peptide. Circulation, 110, 1794-1798. doi:10.1161/01.CIR.0000143073.60937.50

[3] Houben, A.J., Beliaars, J.H., Hofstra, L., Kroon, A.A. and De Leeuw, P.W. (2003) Microvascular abnormalities in chronic heart failure: A cross sectional analysis. Microcirculation, 10, 471-478.

[4] Van Tol, B.A.F., Huijsmans, R.J., Kroon, D.W., Schothorst, M. and Kwakkel, G. (2006) Effects of exercise training on cardiac performance, exercise capacity and quality of life in patients with heart failure: A metaanalysis. European Journal of Heart Failure, 8, 841-850. doi:10.1016/j.ejheart.2006.02.013

[5] Niebauer, J., Clark, A.L., Webb-Peploe, K.M. and Coats, A.J. (2005) Exercise training in chronic heart failure: Effects on pro-inflammatory markers. European Journal of Heart Failure, 7, 189-193. doi:10.1016/j.ejheart.2004.07.012

[6] Roditis, P., Dimopoulos, S., Sakellariou, D., et al. (2007) The effects of exercise training on the kinetics of oxygen uptake in patients with chronic heart failure. European Journal of Cardiovascular Prevention and Rehabilitation, 14, 304-311.

[7] Meyer, K., Samek, L., Schwaibold, M., et al. (1997) Interval training in patients with severe chronic heart failure: Analysis and recommendations for exercise procedures. Medicine \& Science in Sports \& Exercise, 29, 306-312. doi:10.1097/00005768-199703000-00004

[8] Meyer, K. (2001) Exercise training in heart failure: Recommendations based on current research. Medicine \& Science in Sports \& Exercise, 33, 525-531. doi:10.1097/00005768-200104000-00004

[9] Bouchla, A., Karatzanos, E., Dimopoulos, S., et al. (2011) The addition of strength training on aerobic interval training program: Effects on muscle strength and body composition in CHF patients. Journal of Cardiopulmonary Rehabilitation and Prevention, 31, 47-51.

[10] Grassi, B., Pogliaghi, S., Rampichini, S., et al. (2003) Muscle oxygenation and pulmonary gas exchange kinetics during cycling exercise on-transitions in humans. Journal of Applied Physiology, 95, 149-158.

[11] Lima, A. and Bakker, J. (2005) Noninvasive monitoring of peripheral perfusion. Intensive Care Medicine, $\mathbf{3 1}$, 1316-1326. doi:10.1007/s00134-005-2790-2

[12] Cohen-Solal, A., Laperche, T., Morvan, D., Geneves, M., Caviezel, B. and Gourgon, R. (1995) Prolonged kinetics of recovery of oxygen consumption after maximal graded exercise in patients with chronic heart failure. Circulation, 91, 2924-2932. doi:10.1161/01.CIR.91.12.2924

[13] Boushel, R. and Piantadosi, C.A. (2000) Near-infrared spectroscopy for monitoring muscle oxygenation. Acta Physiologica Scandinavica, 168, 615-622. doi:10.1046/j.1365-201x.2000.00713.x

[14] Hiroyuki, H., Hamaoka, T., Sako, T., et al. (2002) Oxygenation in vastus lateralis and lateral head of gastrocnemius during treadmill walking and running in humans. European Journal of Applied Physiology, 87, 343-349. doi:10.1007/s00421-002-0644-y

[15] Neary, J.P., Hall, K. and Bhambhani, Y.N. (2001) Vastus medialis muscle oxygenation trends during a simulated 20-km cycle time trial. European Journal of Applied Physiology, 85, 427-33. doi:10.1007/s004210100481

[16] Kravari, M., Angelopoulos, E., Vasileiadis, I., Gerovasili, V. and Nanas, S. (2010) Monitoring tissue oxygenation during exercise with near infrared spectroscopy in diseased populations - A brief review. International Journal of Industrial Ergonomics, 40, 223-227. doi:10.1016/j.ergon.2009.02.002

[17] Hansen, J.E., Sue, D.Y. and Wasserman, K. (1984) Predicted values for clinical exercise testing. The American Review of Respiratory Disease, 129, S49-S55.

[18] Beaver, W.L., Wasserman, K. and Whipp, B.J. (1986) A new method for detecting anaerobic threshold by gas exchange. Journal of Applied Physiology, 60, 2020-2027.

[19] Nanas, S., Nanas, J., Kassiotis, C., et al. (2001) Early recovery of oxygen kinetics after submaximal exercise test predicts functional capacity in patients with chronic heart failure. European Journal of Heart Failure, 3, 685-692. doi:10.1016/S1388-9842(01)00187-8

[20] Cohen-Solal, A., Chabernaud, J.M. and Gourgon, R. (1990) Comparison of oxygen uptake during bicycle exercise in patients with chronic heart failure and in normal subjects. Journal of the American College of Cardiology, 16, 80-85. doi:10.1016/0735-1097(90)90460-7

[21] Belardinelli, R., Barstow, T.J., Nguyen, P. and Wasserman, K. (1997) Skeletal muscle oxygenation and oxygen uptake kinetics following constant work rate exercise in chronic congestive heart failure. American Journal of Cardiology, 80, 1319-1324. doi:10.1016/S0002-9149(97)00672-3

[22] Kravari, M., Vasileiadis, I., Gerovasili, V., et al. (2010) Effects of a 3-month rehabilitation program on muscle oxygenation in congestive heart failure patients as assessed by NIRS. International Journal of Industrial Ergonomics, 40, 212-217. doi:10.1016/j.ergon.2009.03.006

[23] Kemps, H.M., De Vries, W.R., Hoogeveen, A.R., Zonderland, M.L., Thijssen, E.J. and Schep, G. (2007) Reproducibility of onset and recovery oxygen uptake kinetics in moderately impaired patients with chronic heart failure. European Journal of Applied Physiology, 100, 45-52. doi:10.1007/s00421-007-0398-7 
[24] Dimopoulos, S., Anastasiou-Nana, M., Sakellariou, D., et al. (2006) Effects of exercise rehabilitation program on heart rate recovery in patients with chronic heart failure. European Journal of Cardiovascular Prevention and Rehabilitation, 13, 67-73.

[25] Wisløff, U., Støylen, A., Loennechen, J.P., et al. (2007) Superior cardiovascular effect of aerobic interval training versus moderate continuous training in heart failure patients: A randomized study. Circulation, 115, 3086-3094. doi:10.1161/CIRCULATIONAHA.106.675041

[26] Anagnostakou, V., Chatzimichail, K., Dimopoulos, S., et al. (2011) Effects of interval cycle training with or without strength training on vascular reactivity in heart failure patients. Journal of Cardiac Failure, 17, 585-591. doi:10.1016/i.cardfail.2011.02.009

[27] Hanada, A., Okita, K., Yonezava, K., et al. (2000) Dissociation between muscle metabolism and oxygen kinetics during recovery from exercise in patients with chronic heart failure. Heart, 83, 161-166. doi:10.1136/heart.83.2.161

[28] Kemps, H.M., Schep, G., Zonderland, M.L., et al. (2009) Are oxygen uptake kinetics in chronic heart failure limited by oxygen delivery or oxygen utilization? International Journal of Cardiology, 142, 138-144. doi:10.1016/j.ijcard.2008.12.088

[29] Braith, R.W., Welsch, M.A., Feigenbaum, M.S., Kluess, H.A. and Pepine, C.J. (1999) Neuroendocrine activation in heart failure is modified by endurance exercise training. Journal of the American College of Cardiology, 34, 1170-1175. doi:10.1016/S0735-1097(99)00339-3

[30] Roveda, F., Middlekauff, H.R., Rondon, M.U., et al. (2003) The effects of exercise training on sympathetic neural activation in advanced heart failure: a randomized controlled trial. Journal of the American College of Cardiology, 42, 854-860. doi:10.1016/S0735-1097(03)00831-3

[31] Hambrecht, R., Niebauer, J., Fiehn, E., et al. (1995) Physical training in patients with stable chronic heart failure: Effects on cardiorespiratory fitness and ultrastructural abnormalities in leg muscles. Journal of the American College of Cardiology, 25, 1239-1249. doi:10.1016/0735-1097(94)00568-B

[32] Adamopoulos, S., Coats, A.J., Brunotte, F., et al. (1993) Physical training improves skeletal muscle metabolism in patients with chronic heart failure. Journal of the American College of Cardiology, 21, 1101-1106. doi:10.1016/0735-1097(93)90231-O

[33] Rossiter, H.B., Ward, S.A., Kowalchuk, J.M., Howe, F.A., Griffiths, J.R. and Whipp, B.J. (2002) Dynamic asymmetry of phosphocreatine concentration and $\mathrm{O}_{2}$ uptake between the on- and off-transients of moderate- and highintensity exercise in humans. The Journal of Physiology, 541, 991-1002. doi:10.1113/jphysiol.2001.012910 